(C) [2009] IEEE. Reprinted, with permission, from [Min-Fu Hsieh, D. G. Dorrell, Yu-Han Yeh and Samsul Ekram, Cogging Torque Reduction in Axial Flux Machines for Small Wind Turbines, Industrial Electronics, 2009. IECON '09. 35th Annual Conference of IEEE 3-5 Nov. 2009]. This material is posted here with permission of the IEEE. Such ermission of the IEEE does not in any way imply IEEE endorsement of any of the University of Technology, Sydney's products or services. Internal or personal use of this material is permitted. However, permission to reprint/republish this material for advertising or promotional purposes or for creating new collective works for resale or redistribution must be obtained from the IEEE by writing to pubs-permissions@ieee.org. By choosing to view this document, you agree to all provisions of the copyright laws protecting it 


\title{
Cogging Torque Reduction in Axial Flux Machines for Small Wind Turbines
}

\author{
Min-Fu Hsieh ${ }^{1,2}$, D. G. Dorrell ${ }^{3}$, Yu-Han Yeh ${ }^{1}$, and Samsul Ekram ${ }^{1}$ \\ ${ }^{1}$ Department of Systems and Naval Mechatronic Engineering, National Cheng Kung University, Tainan, 701, Taiwan \\ ${ }^{2}$ Research Center of Ocean Environment and Technology, National Cheng Kung University, Tainan, 701, Taiwan \\ ${ }^{3}$ Faculty of Engineering and Information Technology, University of Technology, Sydney, Australia \\ mfhsieh@mail.ncku.edu.tw, ddorrell@eng.uts.edu.au,p1897102@mail.ncku.edu.tw, samsul.ekram@cgl.co.in
}

\begin{abstract}
This paper presents a technique for cogging torque reduction in an axial-flux permanent-magnet (PM) generator suitable for use in a small wind turbine. These machines can be compact and have high power density; they are axially short with larger diameter which makes then very suitable for a wind turbine. The inherent cogging torque can cause problems during turbine start-up and cut-in. In this paper, a turbine is characterized via the measurement in a wind tunnel. The characteristics are then used to determine the specification for the generator. A method called "hybrid skew" is proposed for cogging torque reduction. 3-D finite element analysis is applied to evaluate the method and a $88 \%$ reduction of peak cogging torque was obtained when combined with another known technique. This significantly improves the turbine performance at low start-up speed while maintaining high power density. The technique can reduce manufacturing confusion in $\mathbf{N} / \mathrm{S}$ pole placement and allow a simple magnet shape for lower cost manufacturing.
\end{abstract}

\section{INTRODUCTION}

Axial-flux slotted permanent-magnet (PM) machines have high power density, high torque density and simple construction and hence are suitable for wind turbine applications [1]. In various axial-flux machine (AFM) constructions, a two-sided configuration is superior to the one-sided construction to balance the axial forces [1]. Studies have been carried to reduce cogging torque in the AFM [2-6]. Aydin et al [2] discussed alternating magnet pole area to reduce the cogging torque. The effects of stator slot displacement and rotor skew on AFM cogging torque were been investigated in [3]. Gonzalez et al [4] considered the magnet shapes combined with stator slot displacement to reduce cogging torque. Cogging torque in radial air-gap PM machines has also been studied in [3] and [4]. Some of these techniques require complex magnet shapes that increase manufacture cost or reduce magnet area that may reduce flux linkage and hence machine overall torque.

There have been studies on AFMs applied to wind turbines [7-10]; however, very few discuss the reduction of cogging torque. Cogging torque in PM machines is undesirable since, in addition to potential noises and vibrations, turbine start-up can be difficult, and this characteristic is inherent in many PM machine arrangements which will significantly affect the performance. The situation is even worse when strong neodymium-iron-boron $(\mathrm{NdFeB})$ magnets are used to enhance the power density. Turbine startup torque can also be increased if a gear box is employed which also has cogging torque - the combined cogging torques can be high. Previous studies have often used coreless designs [7-8] to avoid cogging torque, but this can significantly reduce power density [1].

In this paper, a double-rotor slotted AFM is investigated (unslotted air-gap windings reduce the flux linkage and increases copper loss) for use in a direct-coupled wind turbine, with a solution put forward for cogging torque reduction. The proposed technique called "hybrid skew" and is used in conjunction with stator slot displacement to reduce cogging torque. In this technique, the North Poles have different shapes from the South Poles as shown in Fig. 1. The magnet skew is therefore formed in a different way from the common approach where skew is formed from similar shaped magnets. As can be seen, a complex shape is not required. The advantages of such a configuration are: (a) simple magnet shape for manufacture which reduces cost, (b) clarity N/S pole orientation and placement, (c) little loss in magnet volume to maintain performance. For verification, 3-D finite element analysis (FEA) is used to compute the cogging torque. Apart from the cogging torque reduction investigation, a performance comparison (e.g., air-gap flux density assessment) is made between the proposed hybrid skew approach and a machine which has no skew and exhibits cogging torque.

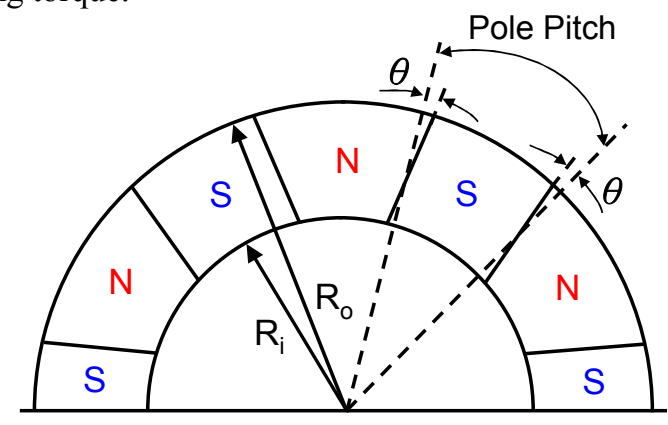

Fig. 1. Hybrid skew in magnet of the investigated axial flux machine.

\section{TURBINE CHARACTERIZATION AND GENERATOR DESIGN}

To determine the specifications of the axial-flux permanent-magnet generator (AFPMG), the turbine needs to be characterized. This is critical since both devices should match each other, this will enable high efficiency power conversion. The speed and torque of the shaft coupling between the turbine and generator need to correspond. The 
test turbine has a diameter of $1.36 \mathrm{~m}$ and was installed in a wind tunnel with a dynamometer to measure the output torque and speed; this is shown in Figs. 2(a) and (b). The measured turbine output power versus rotational speed under various wind speeds $\left(V_{a}\right)$ is shown in Fig. 3(a), and the normalized power conversion coefficient $\left(C_{p}\right)$ curve is presented in Fig. 3(b). From Fig. 3 (b), the maximum turbine conversion rate was found to be $32 \%$ at a tip speed ratio (TSR) of 4.6. The TSR and $C p$ can be defined as:

$$
\begin{aligned}
& T S R=R_{t} \omega / V_{a} \\
& C_{p}=0.5 \rho A V_{a}^{3} / T \omega
\end{aligned}
$$

where $R_{t}$ is the turbine radius, $\omega$ is the turbine angular speed in $\mathrm{rad} / \mathrm{s}, \rho$ is the air density, $A$ is the turbine area facing the wind, and $T$ is the turbine shaft torque. In the tests, the rated condition was set at the wind speed of $11 \mathrm{~m} / \mathrm{s}$, where the turbine shaft output to the AFPMG is $400 \mathrm{~W}$ (Fig. 3(c)). The results in Fig. 3(c) are zoomed from Fig. 3(b). The turbine shaft torques are given in Fig. 3(d). At the rated point, the turbine speed and torque are respectively $660 \mathrm{rpm}$ and 5.79 $\mathrm{N}-\mathrm{m}$. The above information is used to determine the specifications of the AFPMG, as shown in Table I so that the generator can be designed to match the turbine characteristics.

TABLE I

\begin{tabular}{lc}
\multicolumn{2}{c}{ AFPMG SPECIFICATIONS } \\
\hline \hline Rated voltage (V) & 48 \\
Rated power (W) & 580 \\
Number of pole & 12 \\
Number of slots & 18 \\
Rated speed (RPM) & 660 \\
Rated torque (N-m) & 5.79 \\
& $\mathrm{Br}=1.26 \mathrm{~T}$ \\
Magnet (NdFeB) & $\mathrm{Hcb}=11.9 \mathrm{kOe}$ \\
& $\mathrm{Hcj}=20 \mathrm{kOe}$ \\
\hline \hline
\end{tabular}

The designed 12-pole 18-slot AFPMG has a rated output voltage of $48 \mathrm{~V}$ at $11 \mathrm{~m} / \mathrm{s}$ wind; this matches the input of a battery charger. The machine has double outer rotors with NdFeB magnets and a center inner stator, as shown in Fig. 4. Space constraints prevent the reporting of the detailed design process but it follows procedure described in [11]. The major dimensions are shown in Fig. 4. The air-gap is $0.67 \mathrm{~mm}$ and the magnet length is $3 \mathrm{~mm}$. It should be noted that the 12-pole 18-slot configuration has a very high cogging torque. This paper aims to use such a case to emphasize the effectiveness of the proposed technique.

\section{COGGING TORQUe ANALYSIS}

The variation of magnetic energy stored in the air-gap due to the permanent magnet flux at different rotor positions is the source of cogging torque. This can be expressed as [3]:

$$
T_{\operatorname{cog}}=-\frac{1}{2} \phi^{2} \frac{d R}{d \theta}
$$

where $\phi$ is the air-gap flux, $R$ is the air-gap reluctance and $\theta$ is the angular position in electrical degrees. The use of strong rare-earth magnet $(\mathrm{NdFeB})$ requires careful analysis of the cogging torque.

The dual-rotor AFPMG is essentially the integration of two separate motors into one unit, with a single common shaft. Here, two parameters are defined for AFPMG cogging torque analysis: one is the known stator slot displacement factor $\left(K_{d}\right)$ [3] and the other is the "hybrid skew factor" for magnet arrangement proposed in this paper. The displacement factor $K_{d}$ as shown in Fig. 5 is defined as:

$$
K_{d}=t_{d} / t_{s}
$$

where $t_{d}$ is the stator slot displacement and $t_{s}$ is the slot pitch. An appropriate selection of displacement factor for the stator teeth cancels the individual cogging torque developed in a particular air-gap section, which reduces the overall cogging torque. However, the displacement factor may vary between sections. This stator displacement method is used in conjunction with the proposed hybrid skew approach. This produces significant reduction in cogging torque. The most effective combination of these two factors will be investigated using FEA.

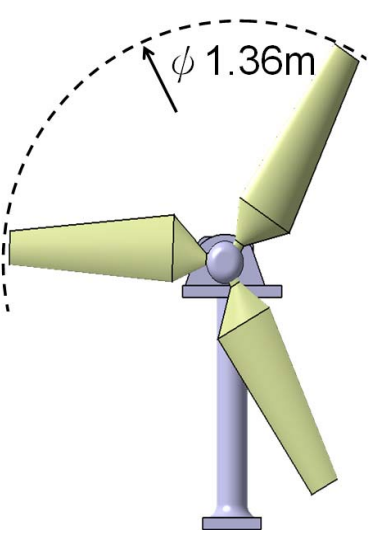

(a)

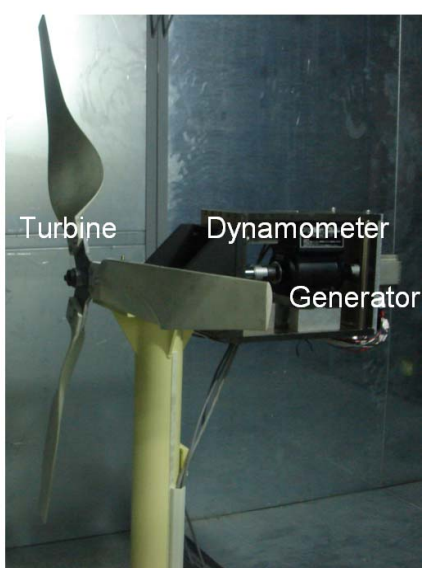

(b)
Fig. 2. (a) The turbine and (b) experimental setup (wind tunnel and dynamometer).

The definition of hybrid skew is given in Fig. 1, for which two types of arrangement can be considered. These are illustrated in Fig. 6 (a) and (b) where the magnets of the upper and lower layers can be arranged symmetrically or asymmetrically. In the asymmetrical case (Fig. 6(b)), the skew in the magnet of one rotor layer is opposite to that in the other. For the symmetrical construction (Fig. 6(a)), the skew is the same for both layers. From a manufacturing point of view, the symmetrical construction is preferable since the confusion in N/S pole placement can be reduced (i.e., all $\mathrm{N}$ Pole magnets have the same shape which is different from the identical S Pole magnets). Although magnet skew is a popular way to reduce cogging torque [3-4], fringing in magnetic flux path may result in torque ripple or overall torque reduction. The objective of the proposed technique is to reduce cogging torque without sacrificing machine performance. 


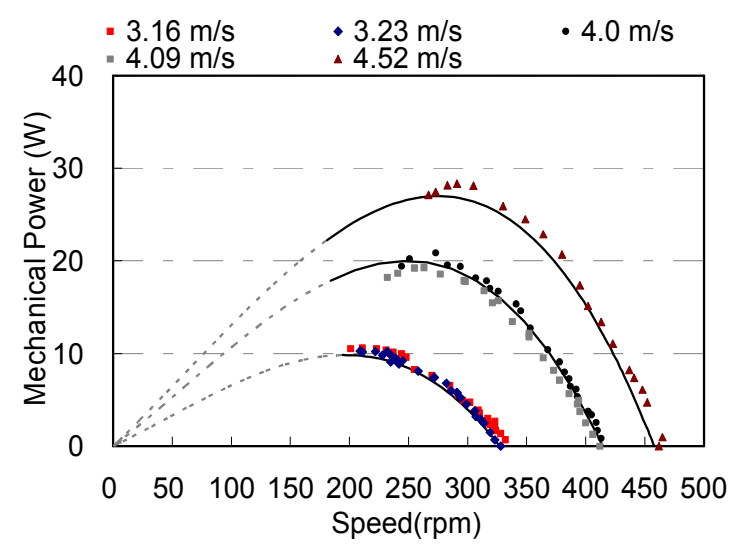

(a)

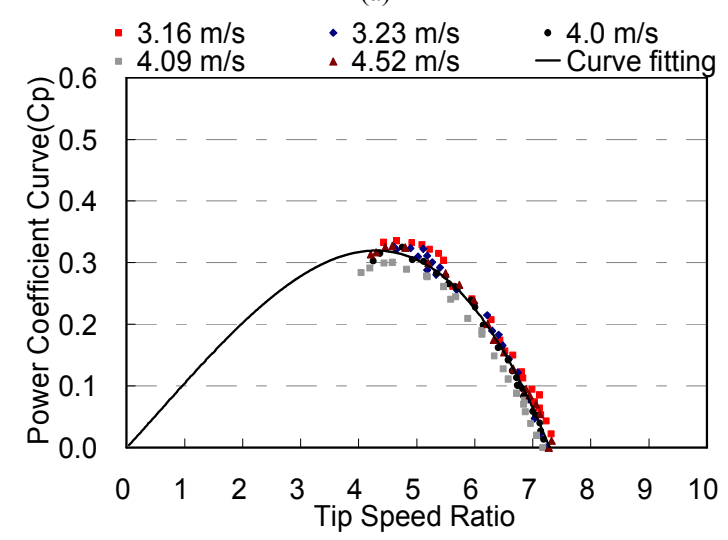

(b)

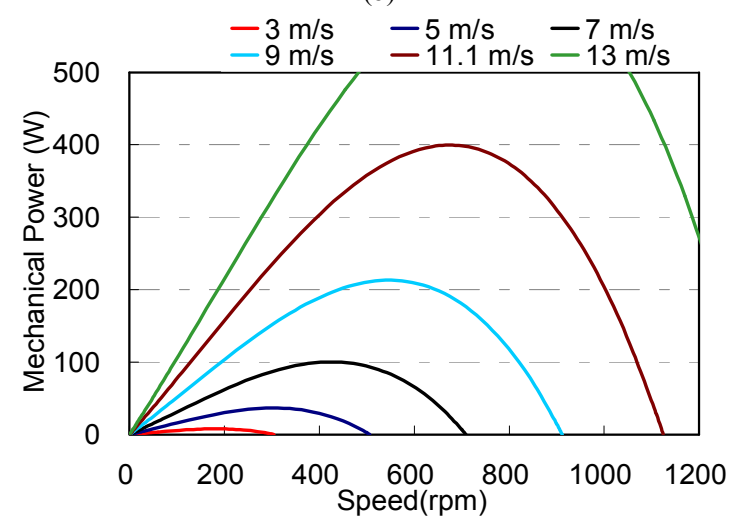

(c)

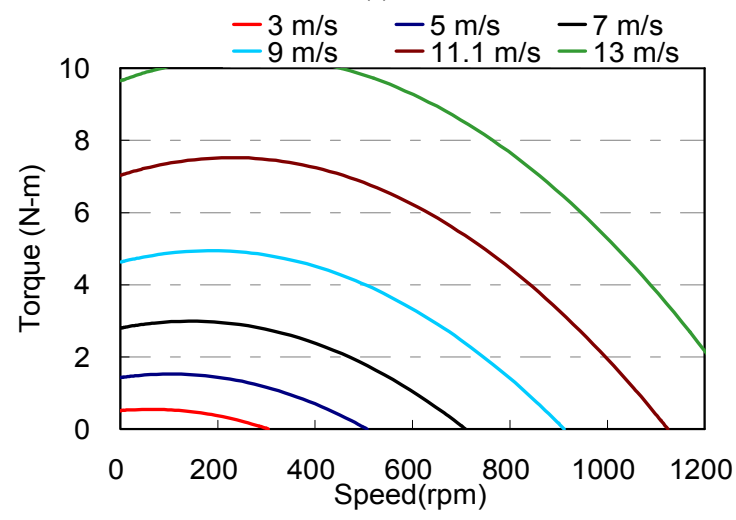

(d)

Fig. 3. Turbine Characteristics: (a) measured power-speed curves, (b) $C_{p}$ curve, (c) expanded power-speed curves and (d) torque-speed curves.

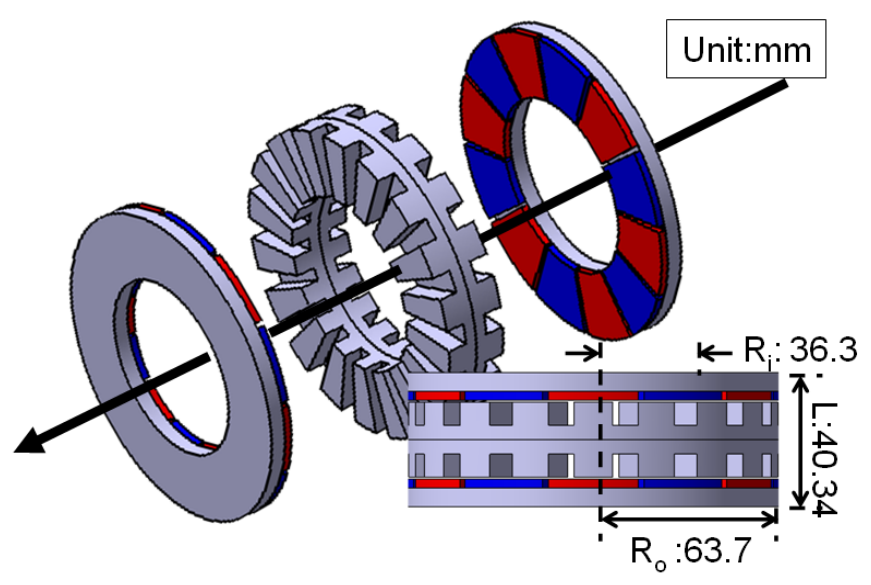

Fig. 4. The designed 12-pole 18-slot AFPMG and main dimensions.

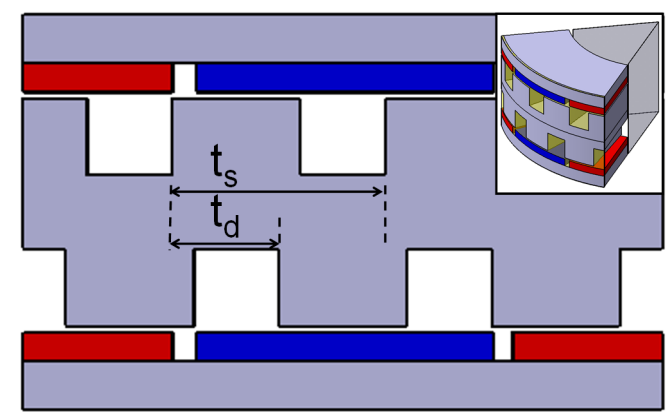

Fig. 5. Definition of stator displacement.

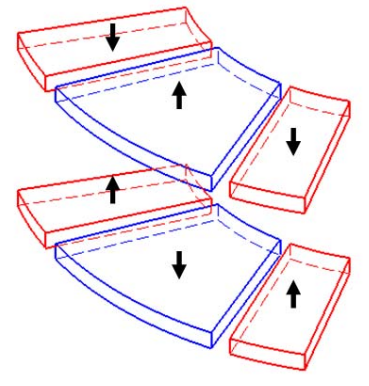

(a)

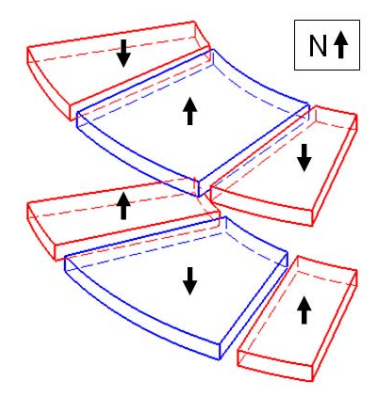

(b)
Fig. 6. Hybrid magnet skew: (a) symmetric and (b) asymmetric skews.

\section{Simulation Results}

The 3-D finite element package JMAG [12] is used to carry out the simulation and analysis of the cogging torque. The finite element model is shown in Fig. 7. The sole action of slot displacement is first investigated. Fig. 8 shows the cogging torques for various slot displacements. These are normalized to the case where there is no skew and $K_{d}=0$. As can be seen, $K_{d}=0.1875$ has the least cogging torque for the 12-pole, 18-slot arrangement. This displacement factor $\left(K_{d}=\right.$ 0.1875 ) will be used in conjunction with the hybrid skew for further cogging torque reduction. 

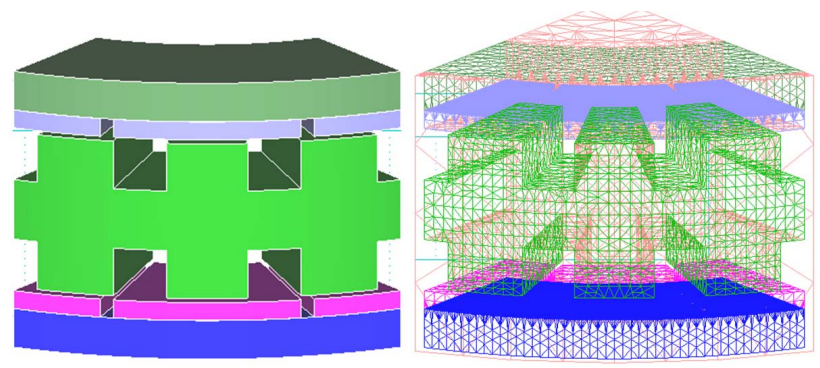

Fig. 7. Finite element model.

To investigate the sole effect of the hybrid skew technique, the two configurations, i.e., asymmetrical and symmetrical, are both analyzed. The cogging torque for varying skew angles with $K_{d}=0$ is shown in Fig. 9. As can be seen, the two configurations have a similar cogging torque magnitudes, with the lowest peak cogging torque occuring at $\theta=2.5$ degrees although the shapes vary considerably. The cogging torque waveforms for varying hybrid skews at $K_{d}=0$ are shown in Fig. 10. From the above results, it is found that the proposed hybrid skew on its own reduces the cogging torque by $57 \%$ while maintaining the performance.

The simulation results for the proposed skew technique combined with the slot displacement method are presented in Fig. 11. Note that only the symmetrical skew arrangement is used in conjunction slot displacement. As can be seen, the best reduction in peak cogging torque is $88 \%$ compared to the non-skewed magnet case. This shows the method to be effective and capable in reducing cogging torque to a much lower level.

An air-gap flux density comparison is shown in Fig.12. The average of the air-gap flux density in the machine when the cogging torque is reduced is similar to the original arrangement without skew or slot displacement. This confirms that the proposed method is capable of significantly reducing cogging torque without affecting the machine performance.

The target turbine has a start-up speed of $3.16 \mathrm{~m} / \mathrm{s}$, which produces an output torque of $0.6 \mathrm{~N}-\mathrm{m}$ according to Fig. 3. The peak cogging torque produced by the proposed technique is very small and should not affect power output. Also, vibration and noise will be reduced so that the overall performance of the wind turbine is enhanced and improved. If a non-skewed machine is used in the turbine then it will be very difficult to start.

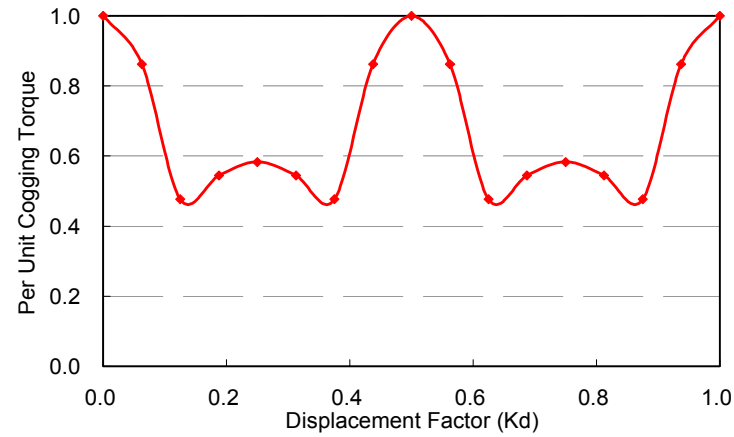

Fig. 8. Peak cogging torque (per unit) for different displacement factor $K_{d}$.

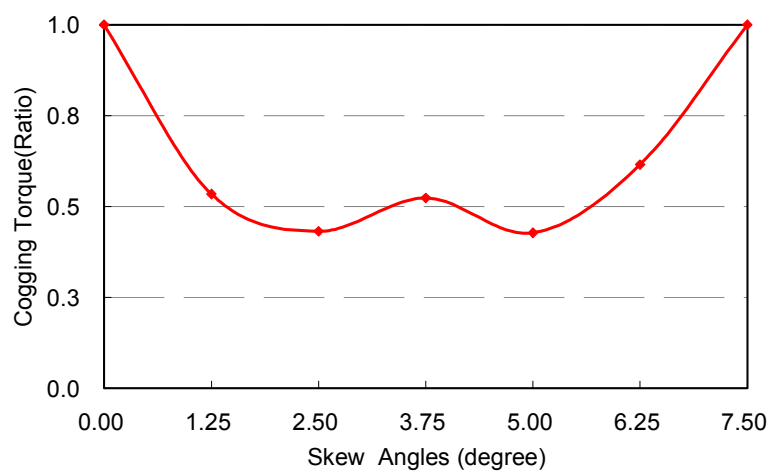

Fig. 9. Peak cogging torque for various skew angles (based on non-skewed).

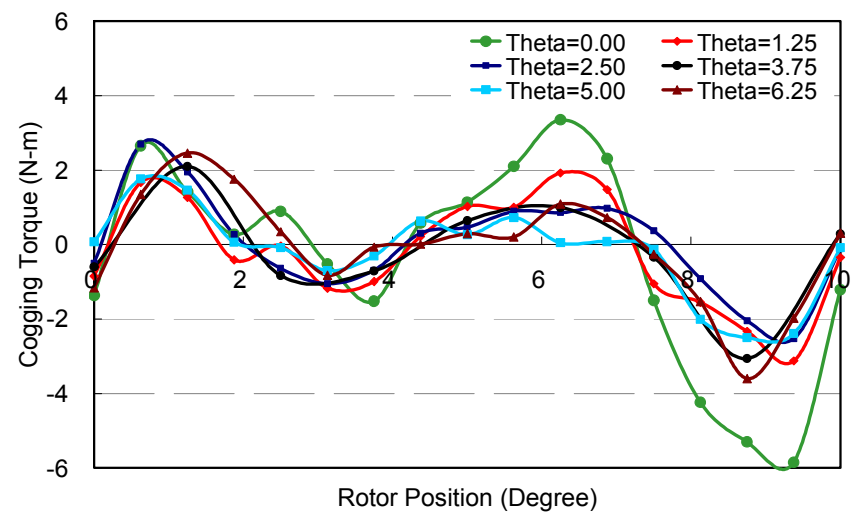

(a)

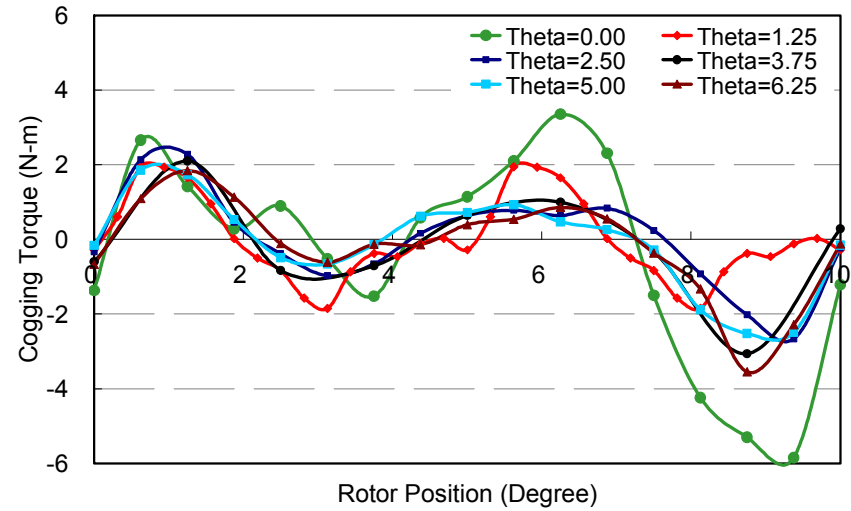

(b)

Fig. 10. Cogging torque for varying skew angles $\left(K_{d}=0\right)$ : (a) symmetrical and (b) asymmetrical.

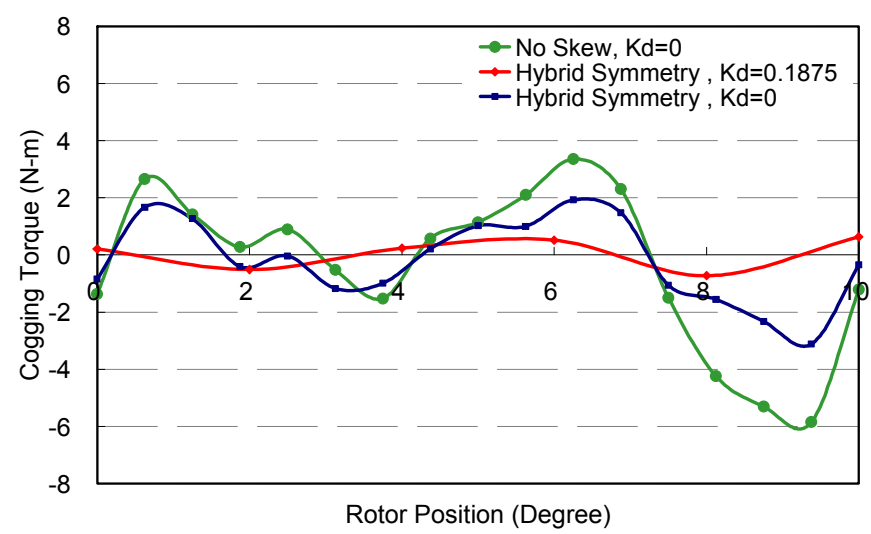

Fig. 11. Cogging torque for various combinations. 


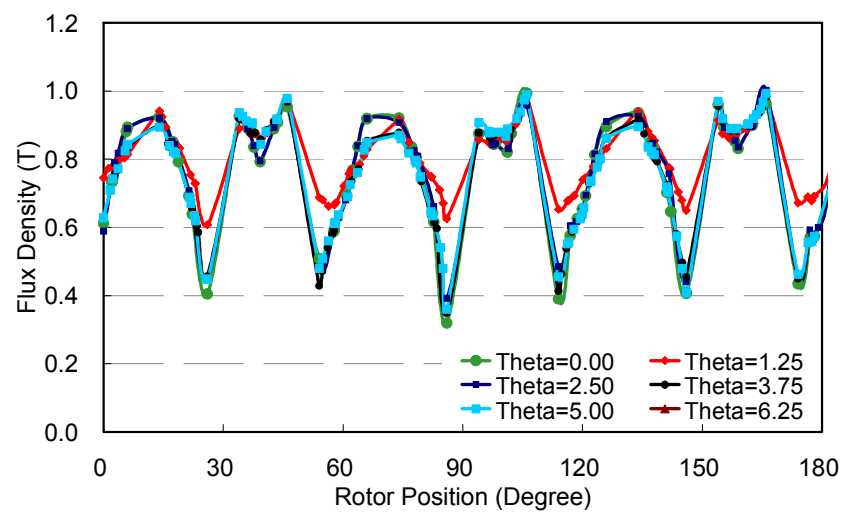

Fig. 12. Air-gap flux density for non-skewed, hybrid symmetrical skew and hybrid symmetrical skew plus slot displacement (Theta $=0$ means nonskewed).

\section{CONCLUSIONS}

A technique called "hybrid skew" has been developed for cogging torque reduction in an axial-flux permanent-magnet generator. This machine is aimed at use in a small wind turbine. A challenging 12-pole 18-slot axial flux machine with high cogging torque has been investigated. 3-D finite element analysis was used to carry out the simulation. It was found that the proposed method, with a hybrid skew $\theta=2.5$ degree, will work with another known technique (slot displacement factor $=0.1875$ ) to achieve an excellent $88 \%$ reduction in peak cogging torque compared to the nonskewed arrangement. Consequently, start-up of the wind turbine will be possible. Without cogging torque improvement it will be difficult for the machine to start. In addition, the overall performance will not be affected by the developed technique and there will be a reduction in manufacturing complexity and cost.

\section{REFERENCES}

[1] Y. Chen, P. Pillay and A. Khan, "PM wind generator topologies, "IEEE Trans. Indus. Appl., vol. 41, no. 6, pp. 1619 - 1626, 2005.

[2] M. Aydin, Q. Ronghai and T. A. Lipo, "Cogging torque minimization technique for multiple-rotor, axial-flux, surface-mounted-PM motors: alternating magnet pole-arcs in facing rotors," IEEE Industry Applications Society Annual Meeting, vol.1, pp.555-561, Oct. 2003.

[3] A. Letelier, J. A. Tapia, R. Wallace and A. Valenzuela, "Cogging torque reduction in an axial flux PM machine via stator slot displacement and skewing," IEEE Trans. Indus. Appl., vol. 43, no. 3, 2007.

[4] D. A. Gonzalez, J. A. Tapia and A. L. Bettancourt, "Design consideration to reduce cogging torque in axial flux permanent-magnet machines," IEEE Tran on Magn., vol. 43, no. 8, pp.3435-3440, Aug. 2007.

[5] Y. Yang, X. Wang, R. Zhang, T. Ding, and R. Tang, "The optimization of pole arc coefficient to reduce cogging torque in surface-mounted permanent magnet motors," IEEE Trans. Magn., vol. 42, no. 4, pp.1135-1138, Apr. 2006

[6] Z. Q. Zhu and D. Howe, "Influence of design parameters on cogging torque in permanent magnet machines," IEEE Trans. Energy Conv. vol. 15 , no. 4, pp.407-412, Dec. 2000.

[7] T. F. Chan and L. L. Lai, "An axial-flux permanent-magnet synchronous generator for a direct-coupled wind-turbine system," IEEE Trans. Energy Conv., vol. 22, no. 1, 2007.

[8] M. Sadeghierad, H. Lesani, H. Monsef, and A. Darabi, "Design considerations of high speed axial flux permanent magnet generator with coreless stator," in proceedings the 8th International Power Engineering Conference, pp. 1097-1102, 2007.

[9] E. Muljadi, C. P. Butterfield, and Y.-H. Wan, "Axial-flux modular permanent-magnet generator with a toroidal winding for wind-turbine applications," IEEE Trans. Indus. Appl., vol. 35, no. 4, 1999.

[10] S. Brisset, D. Vizireanu, and P. Brochet, "Design and optimization of a nine-phase axial-flux PM synchronous generator with concentrated winding for direct-drive wind turbine," IEEE Trans. Indus. Appl., vol. 44, no. 3, 2008.

[11] Jack F Gieras, Rong-Jie Wang and Maarten J. Kamper, Axial Flux Permanent Magnet Brushless Machines, Kluwer Academic Publishers, London, 2004

[12] JMAG, Simulation Technology for Electromechanical Design, 2009. 